\title{
Balanced Approach to Aircraft Noise Management
}

\author{
Oleksandr Zaporozhets
}

\begin{abstract}
ICAO Balanced Approach (BA) to aircraft noise management in airports is reviewed in accordance with historical and technological challenges. All four basic elements of the BA are subject to noise exposure control with dominant emphasis on reduction of noise at source and compatible land usage inside the noise zoning around the airports. Noise abatement procedures and flight restrictions are used at any airport due to its specific issues and should be implemented on a basis of cost-benefit analysis. Noise exposure reduction is an intermediate goal, a final goal-to reduce noise impact, which is mostly represented by population annoyance as a reaction to noise exposure, is discussed also.
\end{abstract}

Keywords Aircraft noise certification - Reduction at source $\cdot$ Land-use planning • Aircraft operational measures $\cdot$ Aircraft operating restrictions

\section{From Noise Exposure to Noise Annoyance-Introduction Issues}

Noise has always been a dominant environmental factor in the area of air transportation, first of all affecting residential communities close to airports. Environmental noise, in general, is an obvious example of unwanted technological and social outcomes in continuous human development, with obvious negative health and behavioural aspects for exposed the population. Particularly in Europe, onethird of the reported problems with noise exposure (ranging between 14 and 51\% in the particular EU States) are observed in urban conglomerates mostly connected with population annoyance as a reaction to noise [1]. Among other sources, aircraft noise can also be a substantial source of annoyance. The International Civil Aviation Organisation (ICAO), in line with its own key role, is aware of and continues to

Small introduction explaining the legal framework of ICAO chapters and the difference between standard for certification and research objectives

O. Zaporozhets $(\varangle)$

National Aviation University, Kyiv, Ukraine

e-mail: zap@nau.edu.ua

(C) The Author(s) 2022

L. Leylekian et al. (eds.), Aviation Noise Impact Management, https://doi.org/10.1007/978-3-030-91194-2_3 
address the adverse environmental impacts (aircraft noise is one of them) and strives to limit or reduce the number of people affected by significant aircraft noise [2]. The EU regulations require from airports to inform the authorities and the population on extent of aircraft noise exposure and the number of people affected by this exposure.

Aircraft noise is still the most significant adverse stressor for community-related to the number of environmental factors in the operation and expansion of airports. It is expected to remain the case worldwide for the foreseeable and even remote future. Any new technological changes in the aviation sector may contribute to further increased noise annoyance, especially the introduction of faster possible new generation of supersonic aircraft for business and scheduled air transportation. Even the introduction of electric aircraft, which are expected to be considerably less noisy in comparison with today's aircraft with similar flight performances, will continue to be scrutinised due to their very close operation to residential areas. Thus, the subsequent reduction of annoyance for neighbouring communities will not necessarily be proportional to their actual noise reduction at source. Thus, limiting or reducing the number of people significantly exposed and impacted to aircraft noise is one of the main priorities of ICAO and one of its key environmental objectives. Division on exposed and impacted population is quite important because not every exposed is obligatorily assessed as impacted by noise. There is only around $20 \%$ of the population, which is exposed to significant noise levels over $65 L D N$, usually reacts adversely to it.

Aircraft noise exposure can lead to more than one effect, and the community impacts (usually health effects, which can be chronic) depend on multiple effects [3]: the primary recognised health consequences of community noise exposure are sleep disturbance during night-time and annoyance during composite daytime. The cardiovascular disease and cognitive impairment of children are also major consequences [4]. WHO Reports $[1,5]$ studied the link between environmental noise and diseases (such as cardiovascular disease, sleep disturbance and tinnitus, etc.), and they probably provide the most pertinent evidence of noise impact on human health. Efforts to reduce noise exposure should concentrate on diminishing the annoyance and sleep disturbance, improving the learning conditions for children and lowering the prevalence of cardiovascular diseases and other risk factors [3]. However, the efforts recommended by these guides usually have different coping abilities for all these types of health consequences. All these notions will be extensively addressed by other sections of this book.

In general, the severity of any hazard impacts depends on the level of exposure inside the affected area. If there is no exposure, the impact is absent too. But evidence exists to show that risk has increased worldwide not only due to increases in hazard exposure of population and/or its assets but the vulnerability of the population to hazard is also fundamental to our understanding of general risk for a population to be damaged by the hazard [6] and of the risk to be annoyed by noise in particular.

Human response to noise is varying differently to different environmental noise sources with the same acoustic levels. Therefore, human sensitivity to noise levels depends on the source of noise. This feature is accounted for by the original Schultz interpolation curve, used in Standard ISO 1996-1 (with small modifications from the 
initial one) [7] to define the proportion of people highly annoyed by noise independence with day-night noise index $L_{\mathrm{DN}}(D N L)$. The standard recommends using such dose-response curves for assessing the annoyance. Among the three basic modes of transportation inside urban environments, aircraft noise is the most annoying for the same given $L_{\mathrm{DN}}$ value. For example, at $65 \mathrm{dBA} D N L$, the proportion of the population who are highly annoyed by aircraft noise is $10-20 \%$ higher than for road traffic and railway noise.

For aircraft noise, any flight event (or any aircraft engine run-up at an airport) is leading to scenarios of noise exposure and impact. The same is valid for aircraft engine emission and air pollution, but the probability of hazard exposure and especially following impact due to any scenario is dependent on the specific location of the point of control relative to the flight path. People are impelled to complain when some burden factor in the environment gives rise to any effect and when this stressor reaches a lower limit value (for example, for noise index $L_{\mathrm{DN}} / L_{\mathrm{DEN}}=45$ $\mathrm{dBA}$ or for $\left.L_{\text {night }}=40 \mathrm{dBA}[1,4,5]\right)$. Exposure, in general, is defined as "the people, property, systems, or other elements present in hazard zones that are thereby subject to potential losses" [8].

Today ICAO [2] and ACARE [9] targets and goals are not confined to reducing noise levels: intended noise level reduction (it is level of stressor only) receiver point s not the final result, but it is just an instrument to achieve the real final goal, which is the noise effects mitigation (just an evaluative tool to achieve the real end goal of reducing noise effects). For ICAO, this effect is currently defined as 'a reduction of the number of people affected by aircraft noise', measured through the number of exposed people by noise over given values defined by guidance or through the number of highly annoyed people. This rationale led currently to new approaches and concepts, even realised measures, to reduce the human annoyance (sleep disturbance and other effects of noise impact), for given levels of aircraft noise [10].

Compared with the traditional noise management approach defined by physical effects of sound generation and propagation, annoyance relies therefore on psychological elements. Up to recently, attempts to explain annoyance relied only on nonacoustical factors like sound intensity, peak levels, duration of time in-between sound events, number of events, etc. [11]. The non-acoustical factors ("moderators" and/or "modifiers" of the effect) have still received empirical attention, without a deep theoretical approach, despite the fact that various comparative studies reveal that they play a major role in defining the impact on people [12].

Therefore, protecting residents from aircraft noise appears now to be a dynamic process: The evaluation limits must be repeatedly tested in view of new scientific findings and adapted, if necessary. Besides traditional approaches of the ICAO balanced approach (BA) [13], which includes reducing aircraft noise at source, implementing operational procedures and restrictions (mostly in airports), new or changed existing flight routes and other forms of mitigation, it is needed to embark on a dialogue with neighbouring communities $[14,15]$. The main objective is to address the issue in an environmentally and economically comprehensive way, to preserve potential benefits of air transport for all categories of stakeholders. 


\section{The Global Footprint of Aviation Noise}

An individual's perception of noise makes it clear that sound levels become an unwanted experience when they occur at the wrong place or at the wrong time. The aircraft noise exposure in and around an airport depends upon a number of factors including the types of aircraft operating the airport, the overall number of daily ground and flight operations, the time of day that they occur, the runways and flight routes that are used for departures and arrivals, airport-specific flight procedures, weather conditions, topography, and other operating conditions. The main effect of noise on population, usually caused by aircraft operations in airport, is dependent of noise exposure, but somewhat subjective at the same time. It may depend on a number of non-technical factors related to the cultural, socio-economic, psychological, and physical issues of the exposed by noise individuals, and may vary from no effect to severe annoyance. Thus, the noise impact is more complex and harder to define the exposure. It is therefore a significant challenge to fully understand, predict and characterise the noise exposure and impact of aviation.

The number of people exposed (which covers a number of impacted and other people not reacting on noise) to aircraft noise is the metric normally used to estimate aircraft noise influence few decades ago. For that a MAGENTA model was developed by ICAO's Committee on Aviation Environmental Protection (CAEP), it was used for assessing global (and regional for comparison) exposure to the noise of transport aircraft. Estimates from the ICAO MAGENTA program have shown an improvement in the global noise situation with a reduction in the size of the population within the $65 \mathrm{~dB}$ DNL contours of about $30 \%$ in 2006, relative to the 2000 level. More recently, ICAO developed a range of scenarios for the assessment of future aircraft noise trends [16]. The noise indicators used in these scenarios are the total contour area and population inside (simply talking-exposed population to specific for contour noise level) the yearly average day-night level $D N L$ at 55, 60 and $65 \mathrm{dBA}$ contours. Such indicators were assessed for over three hundred airports worldwide, covering over $80 \%$ of the global air traffic. Aircraft noise exposure was modelled for four scenarios (baseline and low, moderate, and advanced technology [16]):

- Scenario 1 (baseline) assumes the growth of air traffic without any further aircraft technology or operational improvements after 2015.

- Scenarios 2, 3, and 4 assume the same air traffic rise that all new aircraft delivered by manufacturers into the market after 2015 will reduce their noise levels on 0.1 , 0.2 , and 0.3 EPNdB per annum (so called low, moderate and advanced technology improvements), respectively.

Figure 1 shows the total 55 dBA DNL noise contour area from 2010 to 2050. In 2020 , this area was $18,400 \mathrm{~km}^{2}$, and covering the population inside that contour approximately $31 \mathrm{mln}$ people [16]. By 2050, the global $55 \mathrm{DNL}$ contour area is expected to grow up to 2 times, compared with 2020, depending on the technology scenario. In 2050, the total population exposed increases to 34.2 million people due to scenario 4 (quite small—only $10 \%$ of growth — comparing with the baseline value 


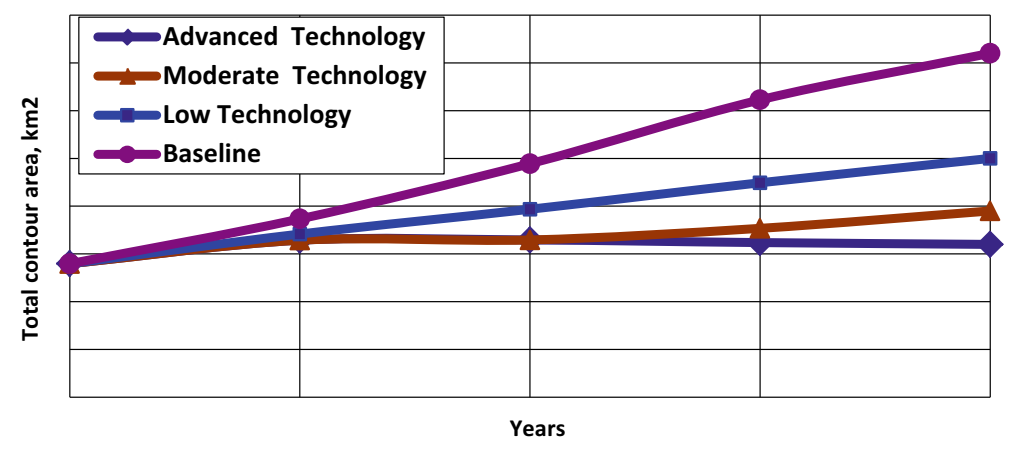

Fig. 1 Total aircraft noise exposure assessment for over three hundreds major airports worldwide, 2010 to 2050: a contour area above $55 \mathrm{dBA}$ DNL $\left(\mathrm{km}^{2}\right)$; b global population exposed to noise above $55 \mathrm{dBA}$ DNL [16]

in 2020), and to 66.9 million people with scenario 2 (near to $100 \%$ growth from 2020).

EASA provided some similar analysis at the European level (EU28 + European Free Trade Association-EFTA) [17]. Current growth in air transportation inside European region is certainly supported by strong demand and represents an average annual rate of $1.5 \%$ over this period. Comparing with ICAO CAEP global trend, the number of yearly flights from and to this EU28 + EFTA area attaining 13.6 million in 2040 with $\sim 2 \%$ growth of air transportation annually, compared to value in 2017 (Fig. 2a) under the most-likely future scenario. It has brought traffic back to the most likely scenario- "Regulation and Growth"-from the 2013 forecast [17] (Fig. 2b), which is close to moderate scenario in ICAO forecasting (Fig. 1).

The total exposed population to noise levels $L_{\mathrm{den}}=55 \mathrm{dBA}$ and over in vicinity of the 47 major European airports was assessed $2.58 \mathrm{mln}$ people in 2017 (Fig. 3). Due to European regulations the noise exposure at night is also important—for the same scenario the $50 \mathrm{dBA} L_{\text {night }}$ contours may disturb $0.98 \mathrm{mln}$ of residents at night. The
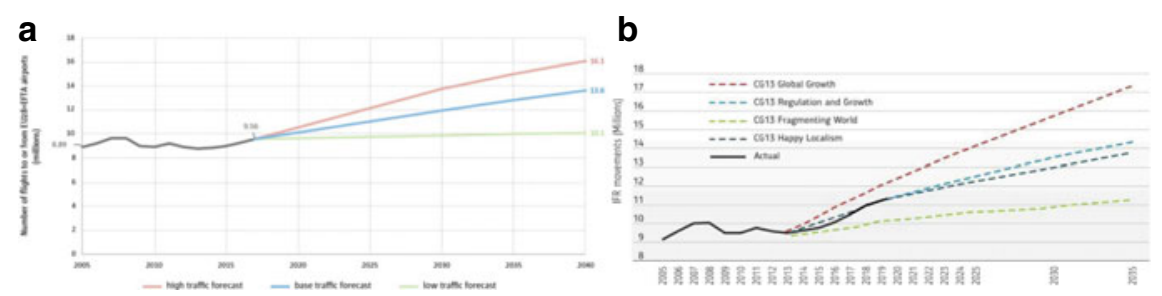

Fig. 2 Number of flights increases by $42 \%$ between 2017 and 2040 under the base traffic forecast: a forecasting from [European Aviation Environmental Report 2019. European Aviation Safety Agency (EASA), European Environment Agency (EEA), EUROCONTROL, 2019. ISBN: 978-929210-214-2 https://doi.org/10.2822/309946. Catalogue No.: TO-01-18-673-EN-N [www.easa.eur opa.eu/eaer]]; b forecasting from [European Aviation in 2040. CHALLENGES OF GROWTH. EUROCONTROL - 2018 (Edition 2)] 


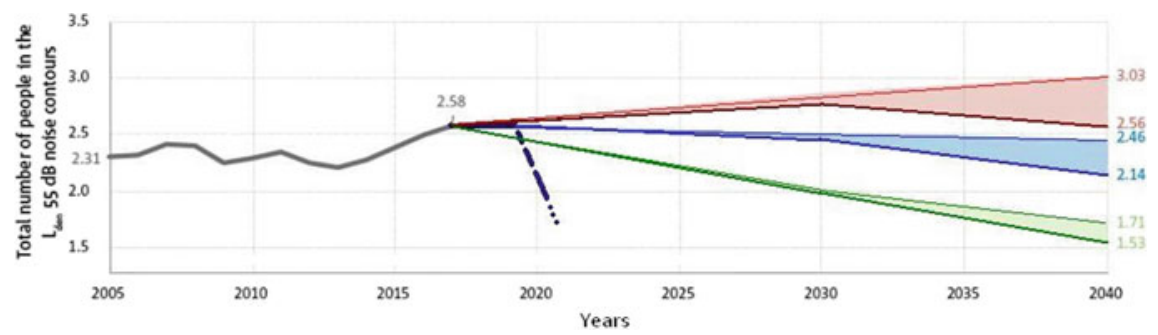

Fig. 3 Latest fleet renewal is able to stabilise noise exposure levels at major EU airports by 2030: for three traffic forecasts-high (red), base (blue) and low (green); upper bound of any forecast reflects the unchanged technology, lower bound-employment of advanced technology for noise control (forecasting from [17])

increase of exposure is equal $12 \%$ and $13 \%$ for $L_{\mathrm{den}}$ and $L_{\text {night }}$ respectively comparing to 2005. nd at the same time the average noise single flight event exposure went down by $14 \%$ over this period [17].

If the latest manufactured aircraft types now entering the European fleet deliver their expected noise reductions (look the Table 1 in text below), the total exposed by noise population (to $L_{\mathrm{den}}=55 \mathrm{dBA}$ and $L_{\text {night }}=50 \mathrm{dBA}$ ) around these 47 major airports should be stabilised for the scenario of Global Growth (mostly optimistic) and possible to decrease by 2030 (in comparison with continuous increase globally). These forecasts assume that airport expansion will be absent, and the population rise will be absent around these airports. However, around 110 airports in Europe could handle more than 50,000 annual aircraft movements [19] by 2040, although there was 82 airports in 2017, thereby new affected by noise population should be expected. Taking in mind the current trend-close to the "Regulation and Growth" scenario - the total number of people exposed to aircraft noise should stabilise in Europe much earlier, likely at the beginning of the 2020s. Of course, such forecasts did not take into account the dramatic effect of the COVID-19 pandemic.

Table 1 New generation aircraft recently introduced or about to enter the market (before the end of 2020) [24]

\begin{tabular}{l|l|l|l|l|l}
\hline $\begin{array}{l}\text { Seat } \\
\text { category }\end{array}$ & $\begin{array}{l}\text { Aircraft } \\
\text { category }\end{array}$ & 2010 reference & $\begin{array}{l}\text { New generation } \\
\text { (examples) }\end{array}$ & $\begin{array}{l}\text { Entry into } \\
\text { service }\end{array}$ & $\begin{array}{l}\text { Fuel saving } \\
\text { reference } \\
(\%)\end{array}$ \\
\hline $51-100$ & $\begin{array}{l}\text { Regional } \\
\text { jet }\end{array}$ & ATR/CRJ & MRJ & 2020 & 20 \\
\cline { 3 - 6 } & E-Jet & E-Jet E2 & 2020 & 24 \\
\hline $101-210$ & $\begin{array}{l}\text { Narrow } \\
\text { body }\end{array}$ & A320/B737 & $\begin{array}{l}\text { A220/A320neo/B737 } \\
\text { MAX }\end{array}$ & $2016 / 2017$ & 20 \\
\hline $211-300$ & \multirow{2}{*}{$\begin{array}{l}\text { Wide } \\
\text { body }\end{array}$} & B767 & A350/B787 & $2015 / 2011$ & $20-25$ \\
\cline { 3 - 6 } $301-400$ & & A330/B777 & A330neo/B777X & $2018 / 2019$ & $14-20$ \\
\cline { 3 - 6 } $401-500$ & & A380/B747-8 & A330neo/B777X & $2018 / 2019$ & $14-20$ \\
\hline
\end{tabular}




\section{The ICAO Noise Certification Procedure for Aircraft}

Standards and recommended practices (SARPs) cover ICAO noise requirements to allow civil aircraft to operate safely for population and environment as a whole. They are contained in Annex 16 [20] to the Convention on International Civil Aviation (in Volume I Environmental Protection-Aircraft Noise). It should be noted that the first generation of aeroplanes with jet engines was not covered by SARPs of Annex 16 and were hencereferred to as non-noise certificated airplanes (among them the aeroplanes Boeing 707 and Douglas DC-8). The noise certification scheme of Annex 16 [20] considers the overall noise produced by the operation of an aircraft, the engine plus the airframe. Through subsequent chapters to Annex 16, these SARPs have been subsequently updated, becoming stricter, since then to reflect and to motivate improvements in aircraft and engine technology (see Subchapter on Reduction of Aircraft Noise At Source below or Chap. 5 and 6 of the book).

Chapter 2 of Annex 16 [20] was the first Standard for aircraft noise and set the limits as a function of maximum take-off mass recognizing the fact that heavier aircraft would be essentially noisier than lighter ones. Those limits in Effective Perceived Noise Level (EPN) dB were set for three measurement points (Fig. 4): at the side of the runway on take-off, under the flight path on climb after take-off, and under the flight path on the approach to landing (this set is still used for limiting noise levels in subsequent chapters of the Annex 16).

Nowadays, newly manufactured aeroplanes must comply with Chap. 14 requirements in ICAO Annex 16 Volume I [20]. In difference with Chaps. 2 and 3, currently the ICAO aircraft noise limits are defined as cumulative values equal to the arithmetic sum of the certification levels at each of three points, which are still the same. Annex 16, Volume I [20] also contains provisions (noise limits and procedures to assess them) for the certification of propeller driven aeroplanes and helicopters.

Each successive chapter of the Annex 16 Volume I [20] has set and enacted higher stringencyin certification conditions, aircraft have become quieter and areas affected by its noise significantly reduced. However, the air traffic is constantly increasing on growing demand for passenger and cargo transportation. ICAO and

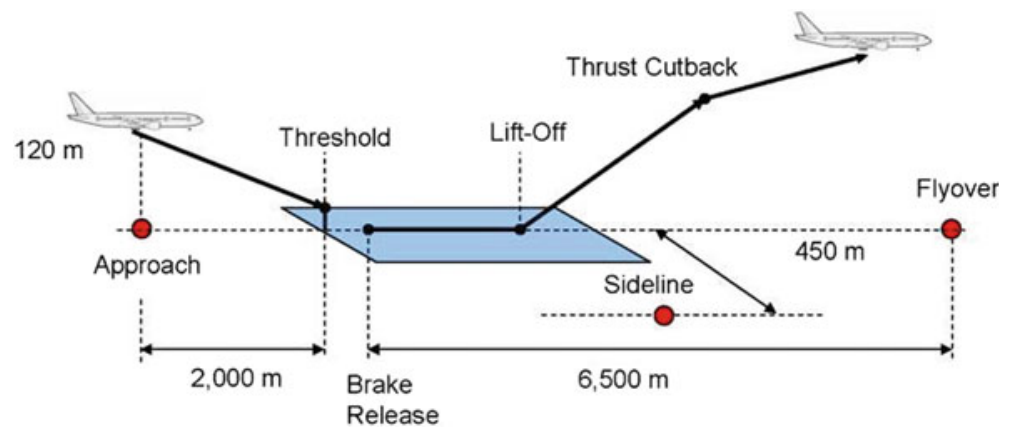

Fig. 4 Aircraft noise certification reference points [16] 
IATA are both assessing and further forecasting during closest decades around 5\% of air traffic increase worldwide due to this constant increase in the community demand for flights (Fig. 2 confirms this trend for European aviation sector, which is going along the most wishful scenario Regulation and Growth). The overall aircraft noise exposure is increasing due to this existing air transportation trend, but overall population exposure by noise may increases also due to constant population desire to provide the great number of activities, including residential, closer to airports. So, additional ways to control the noise exposure and accordingly the impact are required in the vicinity of the airports to provide the sensitive to noise human activities as far as possible. This is organised through noise zoning and appropriate land usage in vicinity of the airports. Further, to keep the size of the zones constant, or even to reduce them, is an important task of noise management in any airport-it is of the same strategic importance as an aircraft noise control in source. Reduction of noise zones benefits those living and working close to the airport.

In 2001 the 33rd Session of the ICAO Assembly adopted a new policy for aircraft noise control globally, referred to as the "balanced approach" to noise management. This new SARPs provided the Member-States with an agreed approach for addressing aircraft noise management components in an effective and economically-responsive way. Because of existent specifics at any region and even at any airport it is eventually the responsibility of any State to implement the various noise protection measures by developing appropriate combinations between them to provide balanced solutions in their programs for managing the noise exposure at airports. The highest effectiveness and economical efficiency are reached with due regard to ICAO provisions and policies while recognizing that States have responsible lawful obligations, including various agreements, laws, and policies on noise management around the airports. The Balanced Approach guidance was developed by ICAO and contained the explanation of all elements in general details [13].

The goal also is to identify the efficient noise abatement measures that achieve the maximum environmental benefit, using objective and measurable criteria, at any specific airport most cost-effectively. At the first step, the noise problem at an airport should be identified and then a comprehensive noise protection program must be developed analyzing the mostly available measures to reduce the noise exposure using four principal elements of the Balanced Approach (BA), namely [13]:

- reduction of aircraft noise at source;

- noise zoning, land-use planning and management;

- noise abatement procedures for aircraft operation; and

- restrictions for aircraft operation.

\section{Reduction of Aircraft Noise at Source}

Reduction of aircraft noise at source is a basic and strategically important among the four principal BA elements. Attempts to reduce the noise the noise emitted by 
the aeroplane are understandable and fundamental in setting new, more stringent standards for noise radiation, so ICAO pays special attention to this element.

Among the principal factors defining the sound level from aircraft flyby over the point on a ground surface are the noise radiated by acoustic sources of the aircraft and the sound propagations factors like the local topography and atmosphere state and both are dependent on weather conditions. Aircraft is a complex acoustic source consisting of engine and airframe components (Fig. 5), and the principal aircraft elements for dominance of any specific acoustic source at a specific flight stage are the following: type of aircraft and engine type, the engine installation (over or under the wing, at the tail, etc.), the aerodynamic configuration of the aircraft, flap and airspeed management procedures being used during the flyby, distances from the aircraft to point of noise control. The airframe and engine contribution to overall aircraft noise are shown in graphs of the Fig. 6, during the principle flight stages of aircraft take-off and landing. The contribution of any acoustic source is dependent of flight mode and it is an important factor for technology improvements in aircraft noise reduction.

\section{a Engine Noise Source Identification}
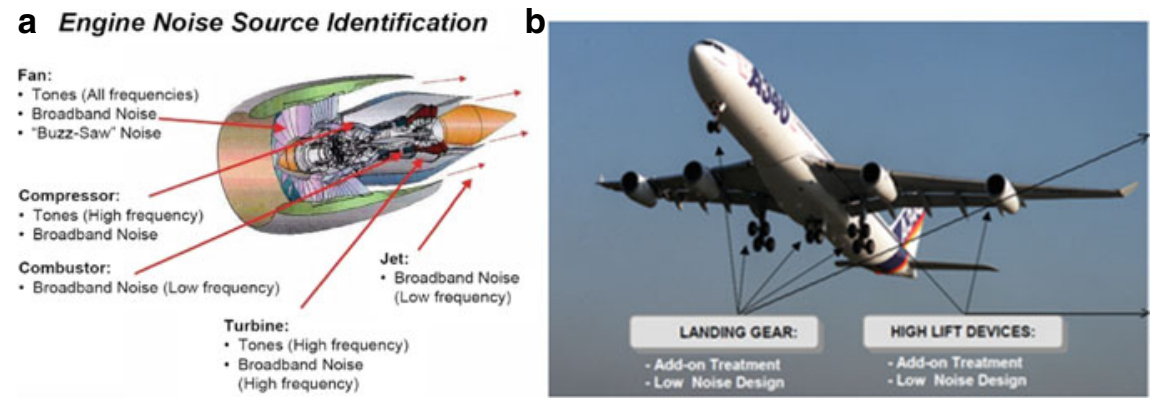

Fig. 5 Engine and airframe noise source identification: a by engine component and sub-component; b airframe component contributions to total aircraft noise for a modern turbofan powered aircraft. $[\mathrm{xx}]$

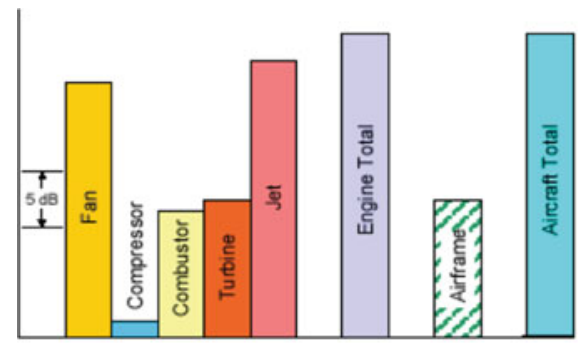

a)

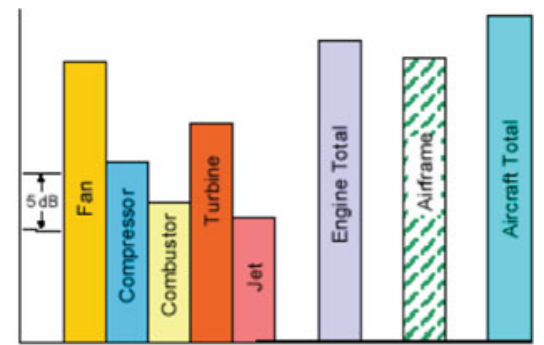

b)

Fig. 6 Sources of acoustic emission during: a takeoff; b landing [Leylekian, L., Lebrun, M., Lempereur, P. 2014. An Overview of Aircraft Noise Reduction Technologies. AerospaceLab Journal, Issue 7, pages AL07-01 (https://doi.org/10.12762/2014.AL07-01)] 
Noise from a single aircraft is primarily produced by the engine, but the total engine noise is the sum of broadband and discrete noise radiated by fan, compressor, combustor, turbine and jet as shown in Fig. 5a). Noise is also created by the airframe as it moves through the air, which is complex also like the engine. It includes the contributions of aerodynamic noise from the high lift devices and the landing gear in air flows (Fig. 5b)).

More detailed information on aircraft noise redaction at source is described in this book in Chap. 5 for existing aircraft and Chap. 6 for expected their future generations. The noise from the first jet aircraft was completely defined by noise radiated by the exhaust jets-it was a loud roar or rumble, very difficult to be reduced by technical means. For the first turbofans (with small bypass ratio $m=1$ ) this dominance of exhausted jet noise became less because the high speed of primary jet was sufficiently reduced and a new acoustic source — a fan — is appeared (Fig. 7a). The achievements of the first technological solutions to reduce engine noise were the basis of the first international standards-Chap. 2 of Annex 16 "Aviation Noise" to the ICAO Convention.

The next generation high-bypass-ratio turbofans (with bypass ratio $m=5-6$ ), which characterised by much higher fuel efficiency, again reduced primary and secondary jet velocities and generated noise in consequence. For these turbofans
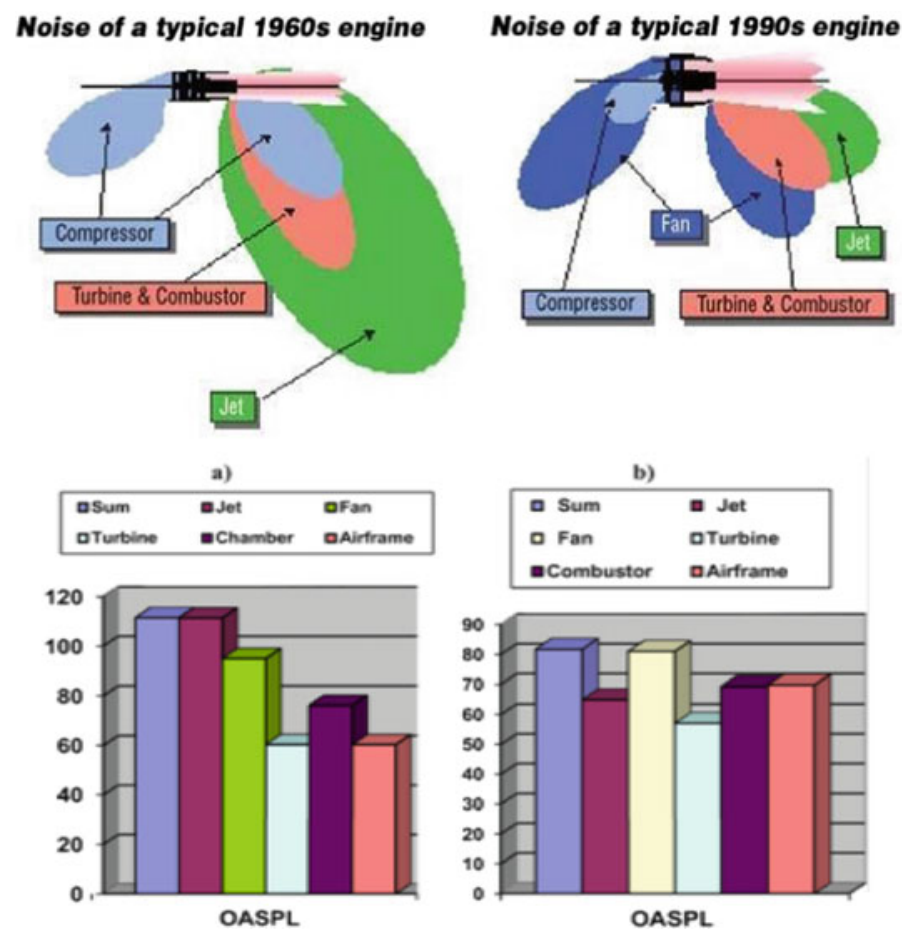

Fig. 7 Engine noise source contributions high bypass benefits and changes in source ranking 


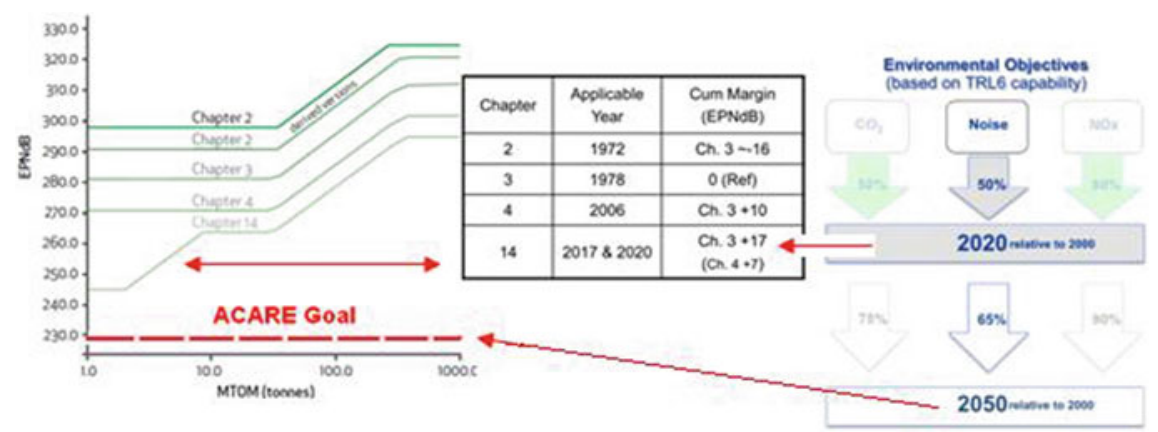

Fig. 8 Comparison between the ICAO requirements and ACARE 2050 goal to aircraft noise

the exhaust jet is still a significant noise source, but not absolutely dominant to total aircraft noise as at take-off so as at landing stages of flight, fan noise became the same significance contributor to overall aircraft noise, especially for flight in approach and landing conditions (Fig. 7b). High bypass technology reduced the engine noise on a value which was fixed in the second ICAO aircraft noise standards-Chap. 3 of Annex 16, Volume 1 "Aviation Noise".

Decreasing the bypass ratio of the turbofans to high $(m=6-8)$ and very high $(m$ $=10$ and beyond) provides new noise reduction benefits (a specific fuel consumption continues to be reduced also) for the aircraft. They were complementarily accomplished with other measures of noise reduction at the engine: reducing the fan noise, optimising the engine cycle, using the contra-rotating rotors, using the sound-absorbing structures and reducing the level of turbulence in the inlet section. These benefits stimulated new changes to aircraft noise standards-Chap. 4 became applicable in November 2008. Chapter 4 includes also provisions related to noise measurement conditions during noise certification testing and began to combine the levels measured at separate three points into a single summary value, used also in the following Chap. 14 requirements to aircraft noise, Fig. 8.

Due to the introduction of quieter aircraft (in accordance with putting more stringent requirements of the ICAO Annex 16 standards at the relevant Chaps. 2, 3, 4 and 14, Figs. 7 and 8) and the global phasing out of Chap. 2 aircraft between 1998 and 2002 as agreed upon in the 28th Assembly of ICAO noise levels from the separate flyovers have been decreased at most airports worldwide. As a result, a modelled overall $65 \mathrm{dBA} L_{\mathrm{DN}}$ noise contour at airport has shrunk in size consistently since 1970-ies (Fig. 9) regardless a rise in total air traffic because of the replacement of noisy ICAO Chaps. 1 and 2 aircraft with much quieter Chaps. 3 and 4 aircraft, further implementation of Chaps. 14 aircraft in operation will decrease them much more.

Aircraft produced today are $75 \%$ quieter than the first civilian jets appeared in operation 50 years ago (Figs. 8, 9 and Table 1). The newly manufactured aircraft typically produce around a half the noise of the aircraft they are replacing, so with this advance the air traffic movements can double without increasing the total noise exposure output. In more detail, The British "Sustainable Aviation Noise Road-Map" 


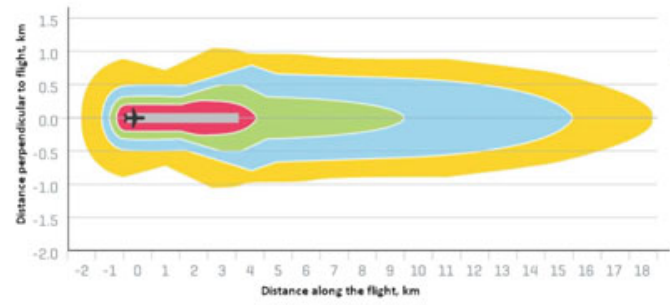

a)

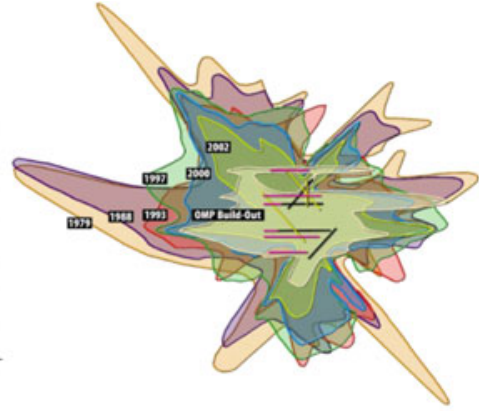

b)

Fig. 9 Aircraft noise exposure reduction by ICAO influence through Annex 16 noise certification norms: a single aircraft departure footprint: Chap. 2 aircraft (represented by B737-200)_yellow contour; Chap. 3 aircraft (MD80 or B737-200 Hush Kit)—blue contour; Chap. 4 aircraft (A320 or B737-800)_-green contour; current Chap. 14 aircraft (A320neo)_red contour; b overall 65 dBA $\mathrm{L}_{\mathrm{DN}}$ noise contour changes at airport O'Hare (Chicago, USA) due to implementation of quieter (with more stringent noise standard requirements to them) aircraft regardless flight traffic growth: till 1979—-the Chap. 2 fleet; till 2000 — the Chap. 3 fleet evolution; at 2002-a fleet with Chap. 2 phase-out; after 2002 - a Chap. 4 fleet evolution

[23] predicts that as current aircraft are replaced by 'Imminent' and 'Future' aircraft, the noise exposure from UK aviation reduces by around $20 \%$, which is close to EU forecasting (Fig. 3).

The noise reduction of engines is provided by further increasing the by-pass ratio of the engine, by the use of a low-speed advanced fan (reduction of the dipole acoustic noise source). Wide-chord fan blades have a twist in height and are made of composite materials. Reduction of the acoustic interaction between the fan impeller and the outlet guide vanes is provided by inclined and specially profiled blades, the number of which is selected to provide the "cut-off" effect. The development of optimised Outlet Guide Vane (OGV) made it possible to significantly reduce discrete and broadband noise.

To achieve ACARE noise reduction goals, engine manufacturers are developing engines under the Advance (bypass ratio $m=11)$ and UltraFan $(m=15)$ programs, which are planned to be completed in 2020 and 2025, respectively. These engines feature for instance: a three-shaft modular design of a high-bypass engine; improved aerodynamics of the impeller machines and a high-pressure ratio up to 60 for Advance and 70 for UltraFan; multiparametric optimisation of aerodynamic and acoustic characteristics, use of the "Intelligent Engine" concept; application of 3D printing technology; an inlet section of a special design contributes to the reduction of the turbulence level at the engine inlet, which in turn reduces the level of vortex noise at the fan inlet; sound-absorbing materials to reduce the tonal noise of a low-pressure turbine.

Effective noise reduction technology-acoustic liners in the nacelle and inside engine ducts - are important in lowering the noise from engine internal sources as it propagates along and out of the intake, bypass duct or core duct (Fig. 10). 

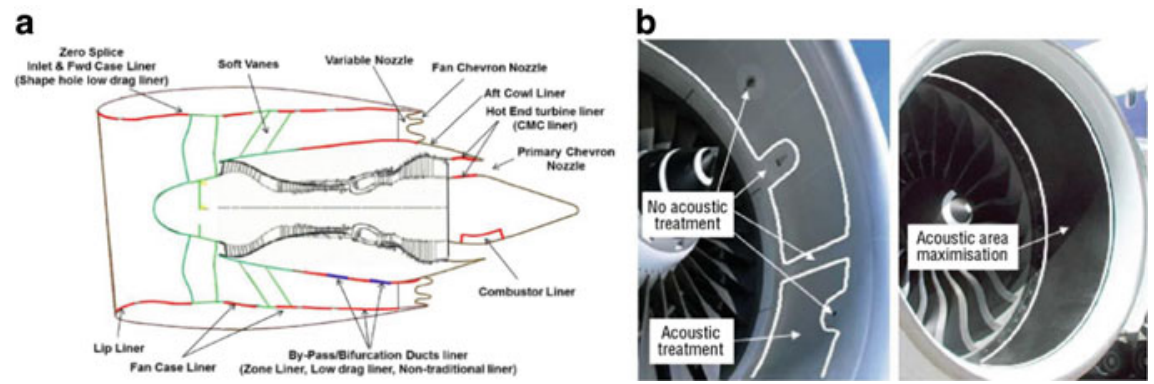

Fig. 10 Engine noise reduction technologies [27]: a acoustic liners inside the high bypass turbofan engine; $\mathbf{b}$ maximising inlet acoustic liner area

To reduce the noise level, it uses a noise active control system, which includes acoustic resonators installed on blades of the fan outlet straightener and devices based on MEMS technology and installed along the inner passage of the engine nacelle. Besides, special porous materials are under development, the use of which can reduce the acoustic emission from the source. The application of such a system makes it possible to reduce the noise level in a source by $\sim 50-60 \%$, or overall aircraft noise reduction achieved by fan forward and fan rearward noise attenuation through acoustic liners was in the range of 10-12 EPNdB (cumulative) on recent aircraft types [21].

The proposed measures allow to reduce engine weight and increase fuel efficiency by $20 \%$ for Advance and $25 \%$ for UltraFan, as well as to reduce noise level and harmful emissions level [24]. The price to pay for very-high-bypass-ratio engines is increased size, weight, and drag, which result in more mission fuel burn. Higher bypass ratio engines require much higher pressure-ratio and temperature gas generator cores, which may have a negative effect on emissions, especially nitrogen oxides (NOx).

During the 50 years of aircraft noise standardisation from ICAO (1st Edition of Annex 16-Aircraft Noise was published in 1969) and continuous strengthening of the requirements from Chap. 2 till current 14 the cumulative reduction was gained up to $\sim 35 \mathrm{~dB}$ (Fig. 5), close to this value is necessary to be reached till the ACARE noise goal at 2050. In 2014, ICAO adopted a new (latest) standard that resulted in a 7 EPNdB decrease compared to the Chap. 4 Standard, so in-production aircraft are prohibited to be manufactured currently with noise higher than Chap. 14 requirements.

\section{Land-Use Planning and Noise Impact Management Issues}

Land-use planning and management is a necessary means to ensure that the human activities nearby airports are consistent with aviation activities [30]. Its main goal is to minimise the population, usually the residents in vicinity of the airport, affected by 
aircraft noise by introducing specific land-use zoning around airports and compatible land usage inside them.

Noise reduction at source alone is not sufficient concerning not only the aircraft, but other transportation sources also. To all of them there is a need to investigate additional measures for noise problem management and noise zoning is among them [1x]. Residential developments near transportation infrastructure (airports for aviation sector) are the places generating the complaints and community reaction directed to reduce noise due to transportation operations. The conflicting trends previously mentioned in designing quieter aircraft and rising air traffic only emphasize the sense of accurately assessing and further managing the impact of aircraft noise on people at their residence site. On the other side of the problem, his may put airport capacity constraints and significantly increase the costs of providing transportation services.

If the main goal in aircraft noise control to reduce noise level at source of its generation, the main goal for noise zoning and land use management to prevent the people from the levels, which are inconsistent with their health and welfare. These levels are defined as sanitary norms (limits) for the population doing any kind of activity - residential, educational, rehabilitation, etc. For all the existing human activities the noise limits are defined because for all of them the noise is a disturbing factor.

The first task of noise zoning is to define the area around the noise source-an airport in our case - where any of the human activities (land usage) are not possible be permitted. The second task - to define the area without any prohibition for human activities. The territory between them is an area of noise management with any possible measures for noise protection.

Any airport development should be accompanied by a program of aircraft noise management in its vicinity. Otherwise, any noise-sensitive human activities (land usage), introduced without attention to noise from the airport, will eliminate the aircraft operation by restrictions and reduce the airport capacity. In the same way, that aircraft noise must be controlled to prevent existing developments from being further exposed.

Airports are usually located within or close to the limits of large urban areas, in better case a distance to existing noise-sensitive land usage (residential or recreational) may provide human protection from noise exposure and minimise the adverse impacts of their operations. Inside the zone of noise management, it is necessary to organise a set of plans (a program for noise protection) that govern urban planning and management with respect to the airport activities. In reality each airport is different in its operational, social, economic and political situation, as well as in the type of land use in its vicinity. That is why, the airport noise protection program should include a land-use control system to assure that all the prescribed measures comply not only with the airport development plan but also with the plan of urban development and the goals of the communities involved.

ICAO is continuously developing a policy on land use planning and management. Current version is contained in Assembly Resolution A40-17, Appendix F [25], it urges States, complementarily with the development and introduction of quieter 
aircraft, to minimise aircraft noise impact problems through preventive measures of noise zoning and land use management:

(a) locate new airports (or new infrastructure in existing airports during reconstruction) away from noise-sensitive residential areas;

(b) take into account the appropriate protection measures for existing and planned land use at the earliest stage of any new airport development or of an existing airport;

(c) define protection zones around airports associated with different noise limits taking into account population size and growth as well as forecasts of air traffic growth and establish criteria for the appropriate land use (as recommended by ICAO guidances [13, 30]);

(d) enact legislation with supporting guidance and other means to show and recommend how to achieve compliance with those criteria for land use; and

(e) ensure that information on aircraft operations and their environmental effects are available and understandable to communities near airports.

\section{Airport Planning Manual for Appropriate Land-Use Inside Noise Zone}

ICAO's Airport Planning Manual (APM) in Part 2 [30] covers three key issues for compatible coexistence of the airport and urban environment: land-use, land-use planning, and land-use management. For that, the APM describes a variety of possible land-uses with an appropriate estimation of their relative sensitivity to aircraft noise exposure. Also, the guidelines indicate the compatibility or incompatibility of these land uses to noise exposure and also to airport operations themselves.

\section{Land-Use}

Human activities inside the area of land management (other words-land uses) such as natural, agricultural and recreational are usually considered as the most compatible with noise since they are realised outdoors and normally don't involve constant human use.

Commercial and industrial land uses are also considered compatible with aircraft noise because they are normally carried out during the daytime and they do not touch the problem of noise at nighttime-sleep disturbance does not occur, as usually happens in residential areas.

On the other hand, the development of residential and institutional land uses, which include single and multi-family dwellings and community support facilities such as schools, hospitals and churches should not be encouraged in airport surrounding areas, since they are extremely incompatible with noise.

The development of residential and institutional land uses, including all necessary urban components such as schools, hospitals, and churches are extremely incompatible with noise, they should not be encouraged in the airport vicinity, where the noise levels exceed the limits. 


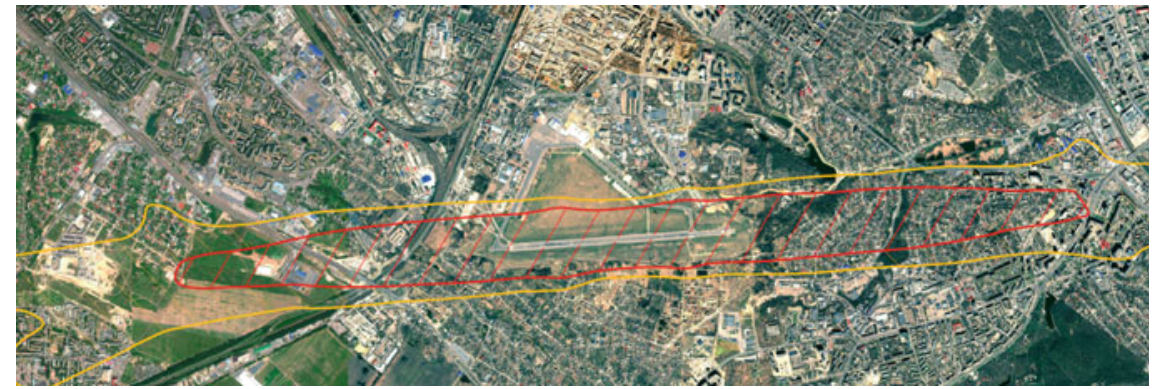

Fig. 11 Example of noise contours Kyiv/Zhulyany international airport-Kyiv, Ukraine

\section{Land-Use Planning}

The problem of airport noise inside the surrounding area can be solved successfully by implementing all possible measures and means, and the proper land-use planning can contribute significantly to the final solution Land-use planning to existing airports is especially important because their possibilities for prompt land-use transformations are limited usually. A trend for continuous reduction in aircraft noise in the source can cause the noise contours to approach closer to the airport boundary. In such a case, the withdrawn area from noise exposure should be prevented from immediate additional encroachment of incompatible land uses. Especially substantial benefits can be acquired from the appropriate land-use planning for new airports under the development without or with quite small constraints for human activities in the surrounding area.

Figure 11 depicts typical noise contours for an airport. In red a noise zone with complete prohibition for any type of human activities is shown, in yellow-a noise zone with specific noise control measures to be implemented. The overlap of urban areas within the NPZ exists and it indicates that a population inside the zones is affected by noise and needs for protection. Noise control measures can be included in program for noise management in airport, adopted by airport and urban authority to ensure that future developments in airport and inside residential areas will be compatible with aircraft noise.

\section{Land-Use Management}

Among the alternatives to regulate land developments inside the surrounding area affected by the airport a number of the modification or restriction of land-uses exists to achieve greater consistency between aviation and human activities or other wordscompatibility between the airport and its environs. These control measures may be divided into three categories, as follows: Planning Instruments, Mitigating Instruments, and Financial Instruments. There are only some examples of these instruments listed below.

\section{Planning Instruments}




\begin{tabular}{l|l}
\hline Planning instruments & $\begin{array}{l}\text { Land-use planning and control authority is covered by local governmental } \\
\text { bodies, as a rule, which must take into account aviation noise exposure } \\
\text { and measures for its reduction. They must account for existing } \\
\text { development, first of all residential and rehabilitation types, and ensures } \\
\text { that future planned development is also consistent between aviation } \\
\text { sector and society, and compatible with various community goals } \\
\text { including the changes in aviation noise exposure }\end{array}$ \\
\hline Noise zoning & $\begin{array}{l}\text { Noise zoning regulations should specify land development depending on } \\
\text { the level of noise exposure and use restrictions, based on certain noise } \\
\text { levels, incompatible with human activities. The regulations should protect } \\
\text { both-the airport and the residents in their mutual developments }\end{array}$ \\
\hline Easement acquisition & $\begin{array}{l}\text { Easements should restrict the use of land to that which is compatible with } \\
\text { aircraft noise levels. They should not violate the right of flights over the } \\
\text { property and to create noise }\end{array}$ \\
\hline
\end{tabular}

Mitigating Instruments

\begin{tabular}{l|l}
\hline Building codes & $\begin{array}{l}\text { Building codes are the legal instruments of requiring the } \\
\text { inclusion of proper sound insulation in new and existing } \\
\text { construction inside areas exposed by noise }\end{array}$ \\
\hline Noise insulation programmes & $\begin{array}{l}\text { Sound insulation is used to reduce interior noise levels } \\
\text { especially for buildings that are not possible to remove out } \\
\text { the areas exposed by noise. Effective noise insulation may } \\
\text { be reached with closed-window conditions, which may } \\
\text { impose additional costs to homeowners or an airport noise } \\
\text { protection fund }\end{array}$ \\
\hline Land acquisition and relocation & $\begin{array}{l}\text { The acquisition of land through purchase by the airport } \\
\text { operator (or another responsible subject in case of new } \\
\text { developments under their authority) and the relocation from } \\
\text { the acquired area of all incompatible with noise levels } \\
\text { residences, administrative and business structures }\end{array}$ \\
\hline
\end{tabular}

Financial Instruments

\begin{tabular}{l|l}
\hline Capital improvements planning & $\begin{array}{l}\text { Capital improvements can be planned in order to locate or } \\
\text { support existing infrastructure networks in areas where } \\
\text { industrial and commercial growth would be compatible with } \\
\text { airport noise }\end{array}$ \\
\hline Tax incentives & $\begin{array}{l}\text { Tax incentives can be provided to occupants of existing } \\
\text { incompatible use facilities in order to encourage structural } \\
\text { improvements to reduce interior noise levels or to encourage } \\
\text { their relocation to quieter areas or otherwise the expansion of } \\
\text { industry as a means to diversify the local economy }\end{array}$ \\
\hline Noise-related airport charges & $\begin{array}{l}\text { Noise reduction and prevention around the airports require } \\
\text { financial investments which may be recovered through airport } \\
\text { noise charges }\end{array}$ \\
\hline
\end{tabular}




\section{Aircraft Operational Measures for Noise Reduction}

The noise of aircraft is subject to ICAO certification SARPs that are intended to apply to the manufactures of aircraft worldwide. This does not prevent local authorities from applying stricter noise limits at specific airports because the land usage at any location may require for that. Due to their unique nature, the certification procedures will not capture the detail and variations that do occur during real operations and, as a result, actual noise levels will not necessarily be the same as those measured during certification.

Local airport rules can include noise limits, curfews and penalties on excessive noise levels. These measures are considered mostly as constraints, they may limit the operational capacity of airports (for example, by restrictions for flights during night) and they may affect the economics of air transportation by limiting the takeoff weight, payload and consequently reducing the economic benefit of specific flight. When analysing operational measures to arrive at an optimum result, it is important to involve all the stakeholders to ensure that interdependencies between the various aspects are fully identified and that any unintended consequences are avoided or minimised to the extent possible. This subchapter discusses the use of aircraft operational measures as a noise reduction method, one of the elements of ICAO's Balanced Approach. It presents a discussion of aircraft procedures for both departures and arrivals/approaches, and their potential effect on noise levels.

\section{Departure Procedures}

Noise abatement operational procedures are being applied in airport operation management to provide locally effective noise reduction to communities active in airport surroundings, from both arriving and departing aircraft. ICAO PANS-OPS, Volume 1, contains a general guidance for the development of a maximum of two noise abatement departure procedures (NADP's) designed to eliminate noise over the normative limits either close in (NADP 1) to the airport, or further out (NADP 2) along the departure path (Fig. 12a). By ICAO guidance both NADPs terminate at $1000 \mathrm{~m}$ altitude, however there may be noise reduction benefits above this, but also the deterioration is possible in some areas, and these should be taken into account as well. Review [31] contains a list of current NADP's with operational and noise mitigation analysis in use by air carriers for a wide range of aircraft types.

At the beginning, the ICAO PANS OPS guidance [32] contained only two recommended noise abatement departures procedures (NADP) for aircraft-ICAO A and ICAO B. This guidance prescribed the choice of either of these two NADP without regard to aircraft acoustic (or noise attenuation technology realised in aircraft design) and flight performance. 


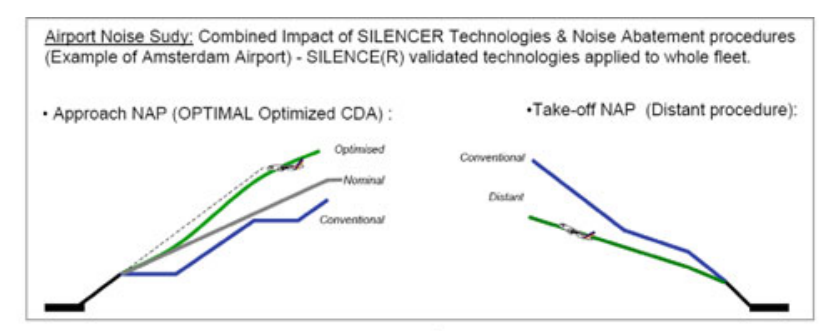

a)

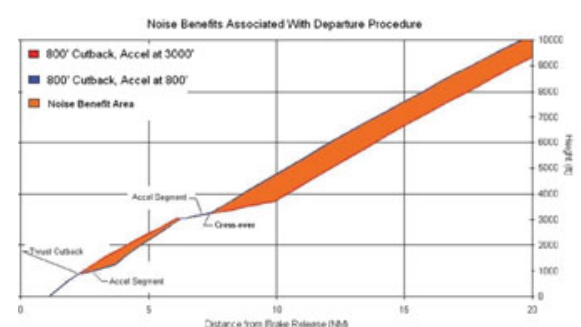

b)

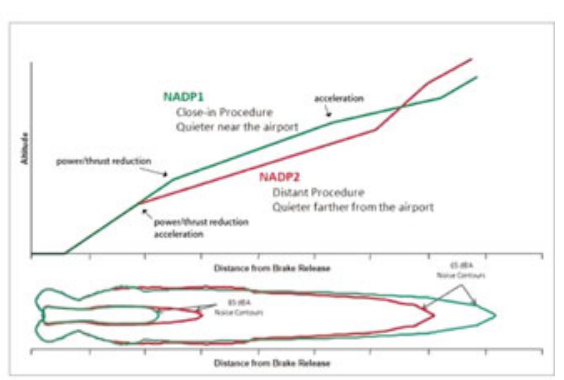

c)

Fig. 12 Departure and approach noise abatement procedures: a SILENCE ${ }^{\circledR}$ validated technologies for NAP at Schiphol airport; $\mathbf{b}$ noise reduction efficiency beneath the flight path; $\mathbf{c}$ noise contour reduction efficiency

After first revision, the ICAO PANS OPS guidance changed the prescriptive ICAO $\mathrm{A}$ and ICAO B flight procedures including the criteria for development of NADP. These criteria are the following:

- Engine thrust reductions till minimum safe aircraft climbing value is prohibited below $800 \mathrm{ft}$ above the runway (Fig. 12b);

- The thrust reduction in aircraft operation cannot be below the thrust level required by the certificated aircraft flight manual if not approved in addition by manufacturers' operations manual;

- The current guidance on NADP and the similar on noise abatement arrival procedures (Fig. 12a) is contained in PANS OPS, Doc 8168 [33], Part I, Sect. 7.

- Designing noise procedures must account for elementary aviation criteria such as regulatory, safety and operability objectives; and it is these criteria that will limit what is ultimately achievable.

NADP 1 and 2 provide air carriers standardized departure profiles for worldwide flight operations, enhancing safety, as well as providing airports and air navigators with a predictable departure metering of aircraft into the en-route airspace structure. These procedures should be the same for all aerodromes. The procedural differences between the NADP 1 and 2 are the thrust or power reduction altitudes and the high-lift device retraction-acceleration segments. Today, the operational opportunities for 
departure noise mitigation also (besides NADP) include: Continuous Climb Operations (CCO), Noise Preferential Routes (NPR), Noise Preferred Runway operations, alternation and respite, and usage of Performance Based Navigation (PBN) - for flight track management.

Arrival noise can be of key importance to residents living under the predominant approach flight paths. There are several reasons for this change in focus: new aircraft noise standards have significantly reduced overall engine noise; the move to more two-engine aircraft which typically have better climb performance; and variations in terminal departure routings provide opportunities for flight track dispersion after take-off. For arrival, airplanes fly the same track within 5-10 miles of the airport at the same altitude according to stabilised approach criteria. Consequently, noise contours close to the airport tend to be more heavily influenced by arrivals than before.

Operational procedures are intended for use by aircraft of the existing fleet for particular local noise issues and have the potential to make an immediate improvement in the environmental impact of aviation around the airport under consideration, as a rule at airports where the noise zoning and land use procedures are realized with omissions. Operational NAPs in use today can be categorised into three broad components: noise abatement flight procedures and spatial management; ground movement management. Figure 13 shows schematically the operational opportunities of the NAPs [23]. It also gives an indication of the areas (distances to runway at departure and arrival) benefiting from some of any procedures outlined.

Given the above, the following guiding principles should be adopted when considering operational opportunities to reduce noise:

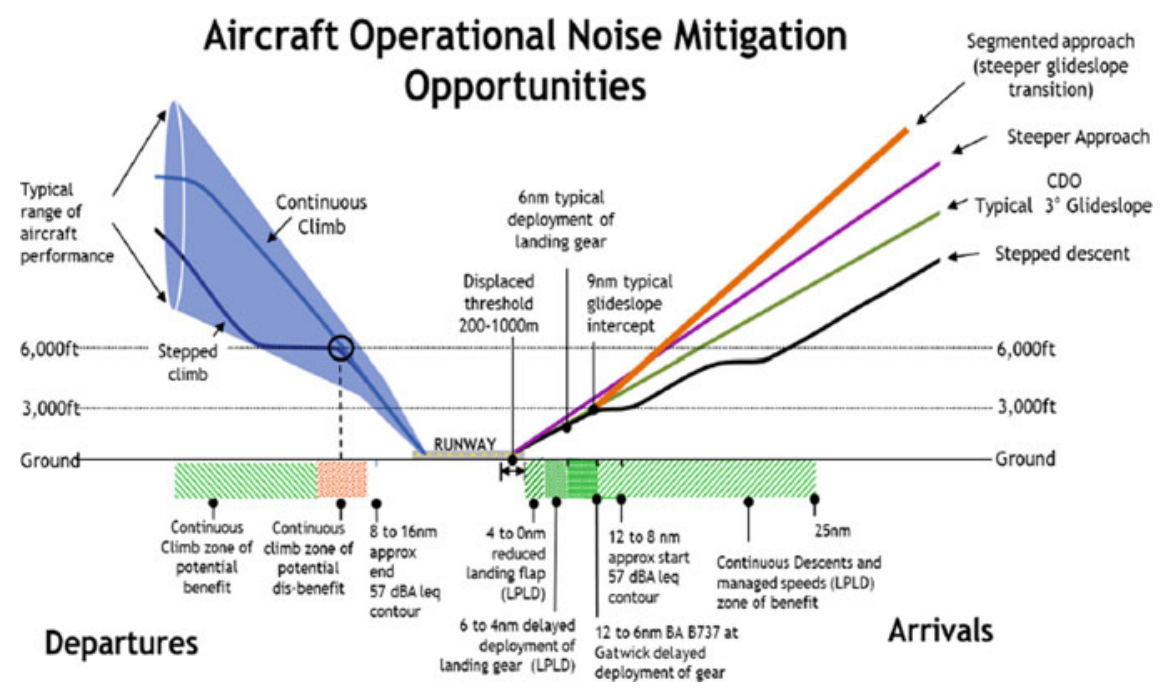

Fig. 13 Aircraft operational noise mitigation opportunities-illustrative, not to scale. [23. Sustainable Aviation Noise Road-Map, 2018 [www.sustainableaviation.co.uk]] 


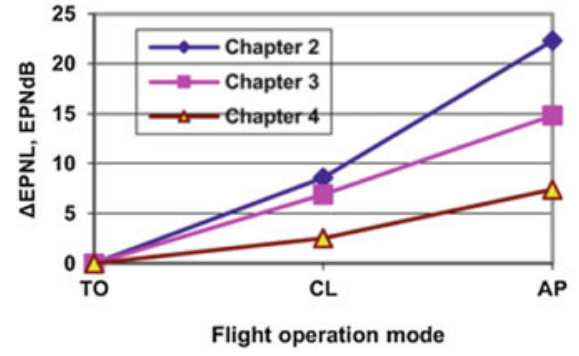

a

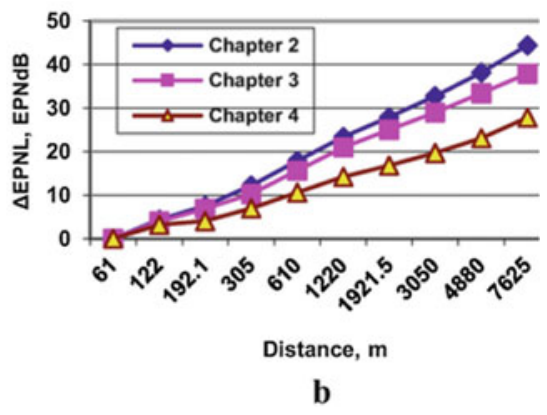

Fig. 14 Aircraft noise standard stringency influence on NAP ability to reduce noise level: a at point of noise control; $\mathbf{b}$ along with flight path distance [10]

(a) Safety must not be negatively affected;

(b) Operational procedures should be developed in accordance with relevant ICAO provisions or regulatory guidance, while allowing for implementation of new procedures as that guidance evolves;

(c) Changes to operational procedures must consider aircraft and operator capabilities and limitations with appropriate approval by the regulator;

(d) Appropriate assessment tools and metrics to support decision making and postimplementation review of conformance should be maintained;

(e) Interdependencies should be considered between other environmental and nonenvironmental impacts and disproportionate trade-offs should be avoided.

Of course, any progress in designing low noise aircraft would therefore lead to relax the stringency of the NAP to be used (Fig. 14).

Arrival/Approach Procedures, the Continuous Descent Arrival/Approach (CDA) can lead to significant reductions in noise, emissions and fuel burn [34]. The CDA concept was elaborated during long time to exclude (or to minimise them) from the approach flight the constant altitude segments and to fly along the descent segments only. The descent flight of an aircraft is made usually with thrust at the flight idle (or very close to it) setting, noise level from descend segments is much less than produced during the level flight segment. The development of the standardised CDAs takes into account environmental aspects (noise and emissions), as well as fuel efficiency issues while ensuring safe and efficient operations of the ATM operations.

Engine noise tends to be lower as the thrust is reduced to slow down or descend, and as technology has developed, engine noise has reduced significantly. However, airframe structures and aircraft configuration contribute to the overall aircraft noise levels, especially during arrivals. They contribute more than during departures for two reasons. Engine thrust is higher during departure and the undercarriage (landing gear) is retracted soon after take-off, after which the high-lift devices (such as flaps and slats), are retracted on schedule as the aircraft climbs, whereas during approach, the engines tend to be at a low power setting. As engines have become quieter, the balance of noise sources has changed and, although engine noise still is the major 
component during departure, there is more of a balance between airframe and engine noise on arrival.

Aspects of flight safety, which are especially important during the descent of the aircraft before landing, come to the fore. First of all, the separation between individual aircraft should be control by Air Traffic Management (ATM) — simply a distance which previously in flight operation was much more easily reached by providing speed changes to aircraft flying along a level flight segment. To manage the separation between a number of continuously descending aircraft is much more complex task for ATM and pilots, it needs for automation on board of the aircraft and in ATM to support the flight safely.

A landing runway may be nominated for noise abatement to provide preferred final approach routes and landings, similar to preferential take-off runways. The first consideration must be safety, but within operational constraints, consideration can be given to community noise concerns.

PBN procedures are being increasingly deployed at airports for departure, arrival, and final approach procedures with measureable benefits on airport capacity, efficiency and emissions reduction as well as reduced noise exposure. There is a general understanding that as a consequence of PBN, procedural predictability and accuracy will be increased with a corresponding concentration of flight over the defined path. This concentration of flight tracks will, in turn, increase the frequency of noise events and hence noise exposure in close proximity to the PBN flight path. As a result, it is important that $\mathrm{PBN}$ procedure design takes population impact into account.

\section{Aircraft Operating Restrictions to Reduce Noise Exposure}

An operating restriction is defined in ICAO's Balanced Approach guidance [13], as "any noise-related action that limits or reduces an aircraft's access to an airport". The guidance recommends to avoid applying any operating constraints as a first measure to eliminate noise exposure, but after considering the exposure reduction to be obtained from the other three BA elements. If the total efficiency of the first three is not enough to reduce noise at any location in the vicinity of an airport, operating restrictions may be implemented, even to exclude it at all.

Usually implementation of any operational restriction is a subject of impossibility to fulfil the requirements to environmental noise at location of interest. In fact, such requirements are defined by the national (State Sanitary Rules) or international (EU Directive) rules and they are used as fundamental basics for establishment the rules for noise zoning around dominant noise sources including the ones in the vicinity of airports. So, noisy type of the aircraft, which is appropriate for doing efficiently transportation work at any route may not be able to fly over the location with installed specific noise limit without violation, even with realised noise abatement procedure. The problem may be due to inaccuracies in the establishment of zoning rules around the airport, or land use (for example, by permitting an activity that is more sensitive to noise than required by the rules of the current noise zone) within the zone. 
Banning of certain noisy operations at noise-sensitive airports was a first type of implemented noise restrictions in aviation sector 30-40 years ago. Evidently, they limited the operational capacity (by installing so-called environmental capacity) of the airports decreasing the economic efficiency. Their number was growing up so quickly that an Extraordinary $28^{\text {th }}$ Session of the ICAO Assembly must consider a consensus on a global framework for the eventual phase-out of aircraft compliant with Volume 1, Chap. 2 of Annex 16, but unable to comply with Chap. 3 Standards. During a period 7 years beginning 1 April 1995 all the States obliged to phase out operations of Chap. 2 aircraft, which had completed 25 years of service on this date (if they were not immediately affected by this requirement). By $200797 \%$ of Chap. 2 aircraft were withdrawn from operation worldwide. This is a type of consensus which was grounded by environmental and economic benefits of the approach.

At the European level, policy-makers reinforced the legislative framework endorsing the "ICAO BA to noise management and sustainable development of air transport". From 2002 to 2014, this regulation was enacted through directive EC $2002 / 30$ providing the Member States with a range of possibilities about its practical implementation. Since 2014, the new EU Regulation 598/2014 [35] has superseded the directive and gives clear and mandatory guidance on how to implement it.

Today hundreds of airports worldwide are implementing aircraft operating restrictions for noise management purposes (Table 2) on a case-by-case basis, whilst limiting capacity, but improving the noise climate around airports (Fig. 15, it is built on data of Boeing data base Airport Noise and Emissions Regulations [36]). Any of them may fall into one or more of the four of the below-described categories, depending on how they are applied:

- Global-restrictions adopted worldwide or inside large regions to be applied at any airport. ICAO and EU decisions on Chap. 2 aircraft phase-out from operation are the examples.

- Local-restrictions adopted by airport authority or by the State to eliminate the operation of noisy aircraft types, for example Chap. 3 aircraft, other way the environmental constraints in a specific airport may reduce its efficient work

- Aircraft-specific-restrictions applied to a specific type based on individual aircraft noise performance, usually at specific route of departure or arrival at airport.

- Partial-restrictions applied for specific flight directions (because aircraft noise becomes inappropriate with new conditions for land use in this direction) or/and for certain runways at the airport, during noise-sensitive time periods (evening and night) of the day, on specific days of the week (weekend).

- Progressive-restrictions which provide for a gradual decrease in the maximum level of traffic or noise energy used to define a limit over a period of time, for example an installation of quota for night-time traffic in airport.

The decisions of the 40th Session of the ICAO Assembly regarding operating restrictions are contained in Assembly Resolution A40-17 [25], Appendix E "Local noise-related operating restrictions at airports". It is a policy document and the ICAO still discourages the application of operating restrictions as the first option to mitigate 
Table 2 Aircraft operating restrictions for noise management purposes in airports

\begin{tabular}{l|l}
\hline Operating restrictions & Explanations \\
\hline Restriction rules & $\begin{array}{l}\text { The rules should define the number of operations not to be exceeded at } \\
\text { an airport usually during the whole day or noise-sensitive time of the } \\
\text { day. They can be global and/or partial measures, i.e. applicable to all or } \\
\text { specific (due to certified level, certified margin, cumulative margin) } \\
\text { operations during an identified period of the day on specific or all } \\
\text { runways of an airport }\end{array}$ \\
\hline Noise quota or budget & $\begin{array}{l}\text { It is generally used to limit the overall noise exposure from aircraft } \\
\text { operations within a given area to established by airport total value over } \\
\text { a given period of time taking in mind that a human reaction to this } \\
\text { noise is defined by the exposure level. The operators begin to use } \\
\text { quieter aircraft, to increase the traffic not violating the noise limit }\end{array}$ \\
\hline Non-addition rules & $\begin{array}{l}\text { The aircraft-specific measures are aimed at prohibiting the operation of } \\
\text { specific aircraft (usually new aircraft) based on their acoustic } \\
\text { performance (certification noise levels) }\end{array}$ \\
\hline Night-time restrictions & $\begin{array}{l}\text { The non-scheduled flights (also non-maintenance based flights, check } \\
\text { flights, and training flights are consistent with this group) may be } \\
\text { forbidden during a specified noise-sensitive time period }\end{array}$ \\
$\begin{array}{l}\text { Sleep disturbance is a dominant noise effect for people in the EU, so } \\
\text { night-time restrictions are of special concern in aircraft noise } \\
\text { protection programs }\end{array}$ \\
\hline Curfews & $\begin{array}{l}\text { Overal or partial operating restrictions, somewhere aircraft-specific, in } \\
\text { airports that prohibit take-off and/or landing during an identified time } \\
\text { period }\end{array}$ \\
\hline
\end{tabular}

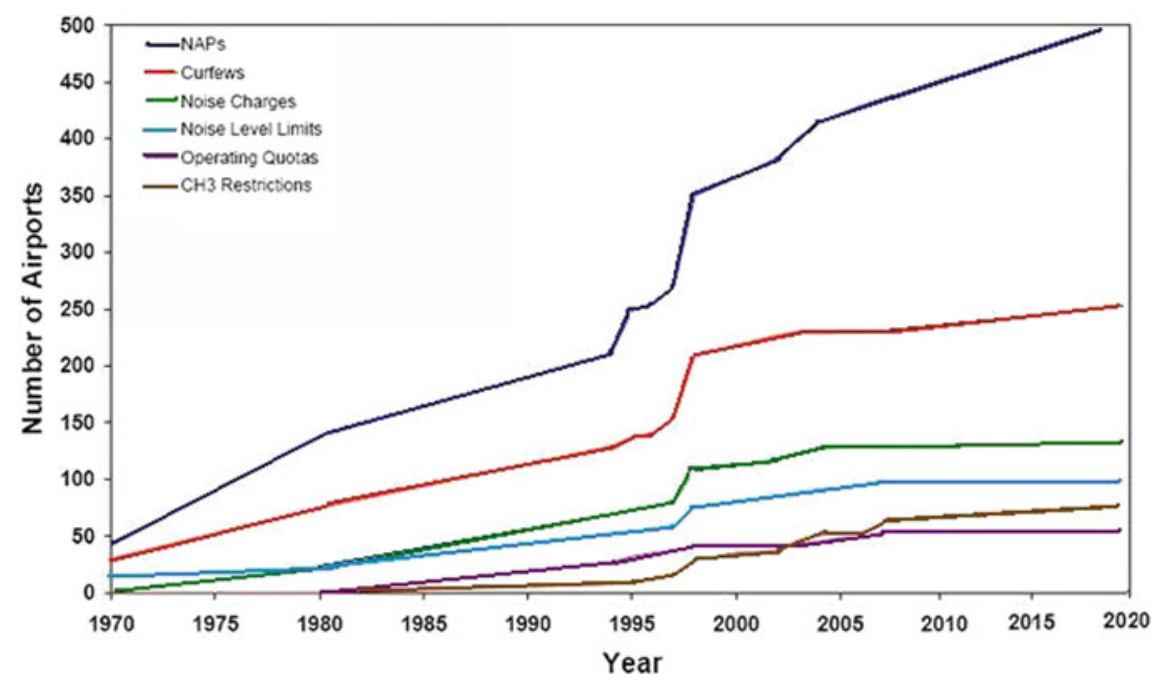

Fig. 15 Growth in aircraft noise restrictions at airports worldwide 
noise exposure around a specific airport. As stated above it is limiting the operational and economic efficiency of the airport work. If the benefits from the first three BA elements are not enough to fulfil the environmental requirements to noise, operating restrictions should be considered in the following way:

(a) be based on the acoustic performance of the aircraft, which should be determined as the noise certification results, consistent with procedures of Annex 16 , Volume I;

(b) be fitted to solving the noise problem of the airport concerned in accordance with the balanced approach principles;

(c) be mostly of a partial nature, not the complete withdrawal of operations at an airport;

(d) take into account the consequences for air transport services, especially if the suitable alternatives are absent (for example, long-haul flights);

(e) conditions of competitiveness should not be violated; for example, exemptions may be granted exemptions for carriers of developing countries;

(f) be introduced stepwise, taking into account the possible economic burden for operators and, if reasonable, to give operators a time period of advance notice for preparations.

Operational constraints can provide a significant reduction in the impact of aircraft noise around airports immediately, but they can increase the financial burden on both airport operators and airlines.

\section{Conclusion: From Noise Exposure to Noise Impact Management}

Until now, all the existing BA elements have been assessed by changes in the noise exposure, mostly via noise contour modelling, and in some cases via monitoring. This allows for the evaluation of noise control measures to determine the most cost-effective and benefitial for environmental protection [37]. In the best cases, the process is performed with public notification and consultation procedures, supplemented with mechanisms for dealing with disputes and complaints. This important approach is recognised in the European Environmental Noise Directive [19]. It requires developing noise action plans with obligatory participation of the public, especially if their residential/rehabilitation area or substantive environmental aspects are impacted by aircraft noise.

Besides the technical elements, which are based on noise intensity metrics completely, the noise annoyance (and other types of outcomes of aircraft noise exposure to neighbouring residents) must now be addressed. This evolution may lead to a new vision of the balanced approach to aircraft noise control in very near future.

It is principal to differentiate between noise exposure and the resulting noise nuisance (annoyance first of all) in different communities and to manage each appropriately. The protection of the residents from aircraft noise exposure is understood 
as a dynamic process, meaning that the evaluation criteria (both for exposure and nuisance) must be repeatedly tested and-if necessary-adapted to new scientific findings [38]. In comparison to the traditional ICAO BA elements, which are defined by physical phenomena of sound generation and propagation, involves non-acoustical factors must now be included to reduce the annoyance. Up to now, annoyance was mainly explained through acoustical factors like sound intensity, peak levels, duration of time in-between sound events, number of events [11]. The non-acoustical factors ("moderators" and/or "modifiers" of the effect) have still received empirical attention but without a deep theoretical approach, despite the fact that various comparative studies reveal that they play a major role in defining the impact on people [12].

Addressing such human-centric concerns, encompassing fear, negative health effects, and other environmental issues may lead to adding a fifth element to the ICAO BA to aircraft noise management around the airports.

It should be a primary objective of future research into environmental noise impact to investigate the interaction of sound level management and perceived noise management. New and additional measures to mitigate noise impact may result from the redirection of attention from sound to noise and to noise annoyance.

Strategies that reduce noise annoyance, as opposed to noise, may be more effective in terms of protecting public health from the adverse impacts of noise and its interdependence with other environmental, operational, economic and organisational issues of airport and airlines operation and maintenance.

\section{References}

1. Environmental noise guidelines for European region. World Health Organisation Regional Office for Europe, Copenhagen, Denmark, p 160. ISBN 97892890 5356. Available online https://www.euro.who.int/_data/assets/pdf_file/0008/383921/noise-guidelineseng.pdf. Accessed date: 30.03.2021

2. ICAO Resolution A39-1 (2016) Consolidated statement of continuing ICAO policies and practices related to environmental protection — general provisions, noise and local air quality ICAO resolutions adopted by the assembly, Provisional edition, Oct 2016, p 138

3. Basner M (2014) Auditory and non-auditory effects of noise on health. Lancet 383(9925):13251332

4. Berglund B et al (1999) Guidelines for community noise. World Health Organisation, revised version, Geneva, p 141. Available online https://apps.who.int/iris/handle/10665/66217. Accessed date: 30.03 .2021 .

5. World Health Organisation (2011) Burden of disease from environmental noise. Quantification of healthy life years lost in Europe. World Health Organisation Regional Office for Europe, Copenhagen, Denmark, p 128. ISBN 978928900229 5. Available online https://www.who. int/quantifying_ehimpacts/publications/e94888.pdf

6. UNISDR (2016) Exposure and vulnerability short concept note: work stream 2, working group, 27-29 January 2016, Geneva International Conference Centre, p 12

7. ISO 1996-1 (2016) Acoustics-description, measurement and assessment of environmental sound—part 1: basic quantities and assessment procedures, International Standard ISO 1996-1. International Organisation for Standardisation, Geneva 
8. UNISDR (2009) Terminology on disaster risk reduction. UN Office for Disaster Risk Reduction, p 30. Available online https://www.undrr.org/publication/2009-unisdr-terminology-dis aster-risk-reduction. Accessed date: 30.03.2021

9. Strategic Research and Innovation Agenda 2017. Update, vol 1. https://www.dlr.de/dlr/Portal data/1/Resources/documents/2017/acare-strategic-research-innovation-volume-1-v2.7-intera ctive.pdf

10. Zaporozhets O, Blyukher B (2019) Risk methodology to assess and control aircraft noise impact in vicinity of the airports. In: Karakoc TH, Colpan CO, Altuntas O, Sohret Y (eds) Sustainable sviation. Springer International Publishing, Springer Nature Switzerland AG, pp 37-79. Print ISBN 978-3-030-14194-3. https://doi.org/10.1007/978-3-030-14195-0_3

11. Janssen SA, Vos H, van Kempen EE, Breugelmans OR, Miedema HM (2011) Trends in aircraft noise annoyance: the role of study and sample characteristics. J Acoust Soc Am 129(4)

12. Job RFS (1988) Community response to noise: a review of factors influencing the relationship between noise exposure and reaction. J Acoust Soc Am 83:991-1001

13. ICAO (2004) Guidance on the balanced approach to aircraft noise management. ICAO Doc 9829, AN/451, Montreal

14. Woodward JM, Lassman Briscoe L, Dunholter P (2009) Aircraft noise: a toolkit for managing community expectations. ACRP report 15 , Washington, DC

15. ICAO Circular 351 (2016) Community engagement for aviation environmental management. ICAO Cir. 351-AT/194, 2017

16. ICAO Environmental Report 2019. Aviation and environment. Destination green. 999 RobertBourassa Boulevard, Montreal, QC, Canada, H3C 5H7. www.icao.int

17. European Aviation Environmental Report 2019. European Aviation Safety Agency (EASA), European Environment Agency (EEA), EUROCONTROL, 2019. ISBN 978-92-9210-214-2, https://doi.org/10.2822/309946. Catalogue No.: TO-01-18-673-EN-N. www.easa.europa.eu/ eaer

18. European Aviation in 2040. challenges of growth. Eurocontrol, 2018 (Edition 2)

19. Directive 2002/49/EC of the European Parliament and of the Council of 25 June 2002 relating to the assessment and management of environmental noise, OJ L 189, 18.7.2002

20. ICAO Annex 16 to the Convention on International Civil Aviation-Environmental protection: Volume I-Aircraft noise; Volume II-Aircraft engine emissions; Volume III-Aeroplane $\mathrm{CO}_{2}$ emissions; Volume IV-Carbon offsetting and reduction scheme for international aviation (CORSIA), 2019

21. ICAO, Doc 10127, 2019. Final Report of the Independent Expert Integrated Technology Goals Assessment and Review for Engines and Aircraft

22. Leylekian L, Lebrun M, Lempereur P (2014) An overview of aircraft noise reduction technologies. Aerospace Lab J (7):AL07-01. https://doi.org/10.12762/2014.AL07-01

23. Sustainable Aviation Noise Road-Map, 2018. www.sustainableaviation.co.uk

24. IATA Fact Sheet, 2019. Technology Roadmap for Environmental Improvement Fact Sheet, June 2019

25. ICAO Resolution A40-17, 2019. Consolidated statement of continuing ICAO policies and practices related to environmental protection-General provisions, noise and local air quality

26. X-NOISE, 2015. Evaluation of Progress Towards ACARE Noise Targets. Aviation Noise Research Network and Coordination, X-NOISE EV, Project Number 265943, Deliverable D06.31, Date of preparation: June 2015

27. Astley RJ (2014) Can technology deliver acceptable levels of aircraft noise? Inter-noise 2014, Melbourne, Australia, paper 369, p 12

28. Dobrzynski W, Chow LC, Guion P, Shiells D (2002) Research into landing gear airframe noise reduction. AIAA 2002-2409

29. Hall CA, Schwartz E, Hileman JI (2009) Assessment of technologies for the silent aircraft initiative. AIAA J Propulsion Power 25(6):1153-1162

30. ICAO Document 9184, Airport Planning Manual, Part 2-Land Use and Environmental Control

31. ICAO Document 9888, 2007. Review of Noise Abatement Procedure Research and Development and Implementation Results 
32. Operation of Aircraft. Annex 6 to the Convention on International Civil Aviation Part I International Commercial Air Transport-Aeroplanes. Adopted on 25 February 201, Published by ICAO, p 240

33. Doc 8168 Aircraft Operations (PANS OPS) Volume I Flight Procedures, 6th ed., 2020. Published by ICAO, p 214

34. Continuous Descent Operations (CDO) Manual. Doc 9931 AN/476, 2020, 1st ed., 2010. Published by ICAO, p. 76

35. EU Regulation 598/2014 OF THE EUROPEAN PARLIAMENT AND OF THE COUNCIL of 16 April 2014 on the establishment of rules and procedures with regard to the introduction of noise-related operating restrictions at Union airports within a Balanced Approach and repealing Directive 2002/30/EC. Available online https://eur-lex.europa.eu/legal-content/sv/ALL/?uri= CELEX:32014R0598. Access date: 02/04/2021

36. Airports with noise and emissions restrictions. Database. Available online https://www.boeing. com/commercial/noise/list.page. Access date: 02/08/2021

37. Zaporozhets O, Tokarev V, Attenborough K (2011) Aircraft noise: assessment, prediction and control. Glyph International, Taylor \& Francis

38. Chyla A, Bukała M, Zaporozhets O et al (2020) Portable and continuous aircraft noise measurements in vicinity of airports. In: Systemy s SrodkiTransportu. Bezpieczenstwo I MaterialyEksploatacyjne. Red. Naukowa Leida K., Wos P. Monografia, WydawnictwoPolitechniliRzeszowskiej, Rzeszow, pp 69-80

Open Access This chapter is licensed under the terms of the Creative Commons Attribution 4.0 International License (http://creativecommons.org/licenses/by/4.0/), which permits use, sharing, adaptation, distribution and reproduction in any medium or format, as long as you give appropriate credit to the original author(s) and the source, provide a link to the Creative Commons license and indicate if changes were made.

The images or other third party material in this chapter are included in the chapter's Creative Commons license, unless indicated otherwise in a credit line to the material. If material is not included in the chapter's Creative Commons license and your intended use is not permitted by statutory regulation or exceeds the permitted use, you will need to obtain permission directly from the copyright holder.

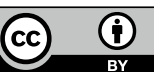

